\title{
8. TRENDS IN INTERNET-BASED ELECTRONIC COMMERCE: RESULTS OF AN INITIAL SURVEY
}

\author{
R.I. Ferguson, P. Cranner, D. Grey, \\ S. Kerridge, A. Slade, J.B. Thompson and
}

A. Williams

Centre for Electronic Commerce, University of Sunderland, St.Peter's Campus, Sunderland, SR6 0DD, ian.ferguson@sunderland.ac.uk, Tel: 01915152754 , Fax: 01915152781

\begin{abstract}
Early results from a survey of organisations undertaking electronic commerce (EC) on the Internet are presented. The survey aimed to establish what hardware and software environments are currently in use, whether bespoke software is being used or whether off the shelf packages to support EC have matured sufficiently to gain acceptance in this market.
\end{abstract}

\section{Keywords \\ Business/Commerce, Database, Hypermedia, Internet}




\section{Current state of Electronic Commerce}

\subsection{Reasons for surveying}

The explosion in popularity of all things Internet flavoured has tempted many commercial organisations to dip their toes into the waters of electronic commerce (Adam, 96). In the rush to gain a foothold in cyberspace, many websites have been hastily created with scant regards for the disciplines of software engineering. As part of Tradepoint (Kerridge, 97), an ongoing European funded project at the Centre for Electronic Commerce at the University of Sunderland, the authors wished to establish the degree of "maturity" of current web-based trading systems. Two measures of this maturity might be the proportion of systems that utilised bespoke software to those that used off-the shelf solutions and the proportion of systems using a structured (database based) back-end to those using a less structured flat file approach(Kalakota, 97). A survey was thus undertaken.

\section{Methodology}

\subsection{Initial Survey vs Complex Survey}

The survey was performed in two stages. Firstly an initial survey of 4 questions was sent via email to the webmasters of 70 randomly selected websites using catalogue based systems to sell products and/or services. Those that replied to the initial questionnaire were invited to submit further details of their operation via a webbased form. This paper describes the results of the initial email-based survey.

\subsection{Selection of companies -}

The Centre for Electronic Commerce maintains a directory of organisations engaged in electronic commerce (Ferguson, 97b). From that list a random selection of 70 organisations was made. Each website was inspected to find the email address of the person responsible for creating/maintaining that site. The questions described in the following section were than emailed to that person.

\subsection{Questions}

The questions were designed to ascertain the extent to which electronic commerce has become established on the Web. Indications of this should be the emergence of standard means of implementing e-commerce systems. The survey aimed to find whether ad hoc implementations were the norm or whether more structured means were in common use. The questions were as follows:- 


\section{Catalogue - Bespoke vs Off-the-shelf}

"Is the catalogue system you use: a) custom made for your site or

b) a proprietary piece of software? (If so which one?)"

It was hypothesised that the emergence of propriety (off-the-shelf) software to support electronic commerce would indicate that a certain level of maturity had been reached by Internet-based EC.

Database Usage
Does your catalogue system use a database? a) Yes. (If so, which one?) or b) No.

The authors suspected that in the rush to enter the field of Internet-based EC (and given an initial shortage of expertise in Web-based programming techniques) many EC systems have been "hacked together" rather than properly engineered. The use of a structured data representation underlying the implementation would indicate that some measure of design had gone into a given system.

\section{Hardware/Operating system -}

What hardware/software does your catalogue system use?

a) UNIX based workstation, b) MS-Windows NT, c) MS-Windows 95, d) MSWindows 3.X or e) Macintosh

In its initial phases of development, the Web was almost entirely based upon UNIX technology(Berners-Lee, 92). As it popularity has increased, a move towards PC technology has taken place on the client side. For the server-side however, UNIX technology has remained popular. UNIX is however perceived (wrongly or rightly) as being a more complex system than PC based operating systems (Net.Genesis, 96) and thus a potential barrier to the spread of EC. The authors wished to ascertain whether this "folk-wisdom" on the usability of UNIX had any effect on the spread of EC.

Geographical Location Whereabouts are you based?a) USA, b) Europe or c) other.

Although the Web was initially a European development (Berners-Lee, 92), the first area in which it has spread into home use (rather than academic) is the USA. The authors wished to investigate whether the provision of EC services in Europe lagged behind the US, and if so, by how much?

\section{Results}

\subsection{Response rate}

Of the 70 emails sent out, 31 responses were received within a 2 week interval. The original data for the survey can be found on-line at the CEC website (Ferguson, 97a). 
3.2 Catalogue - Bespoke vs Off-the-shelf

The answers to question 1 are shown in Figure 1

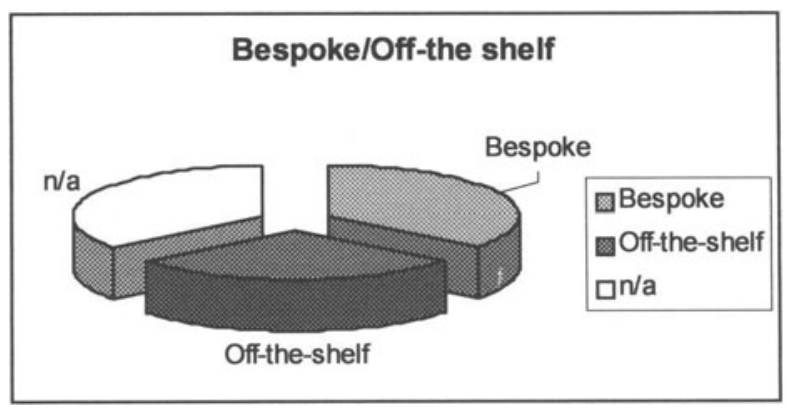

Bespoke 11 Off-the-shelf 9 No-answer or answer not applicable 11

Figure 1 - Bespoke vs. Off-the-shelf systems

\subsection{Database Usage}

The answers to question 2 are shown in Figure 2

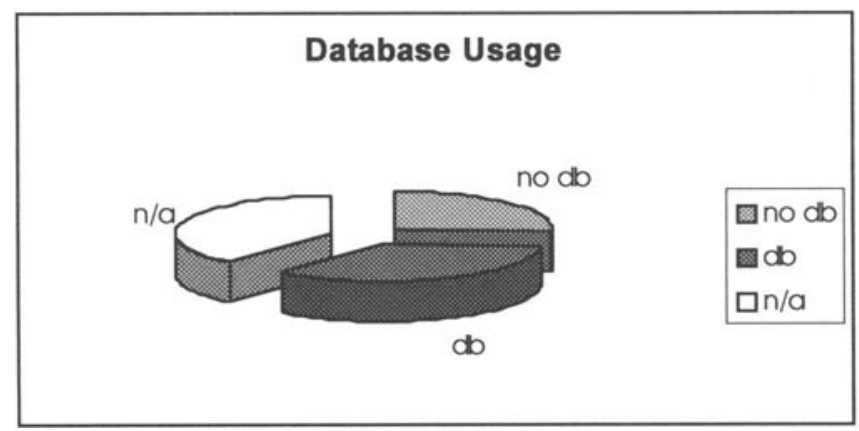

Database 11

No database 8

No-answer or

answer not

applicable 12

Figure 2 - Database vs. no database System 
For the systems that did use a database, the breakdown is shown in Figure 3.

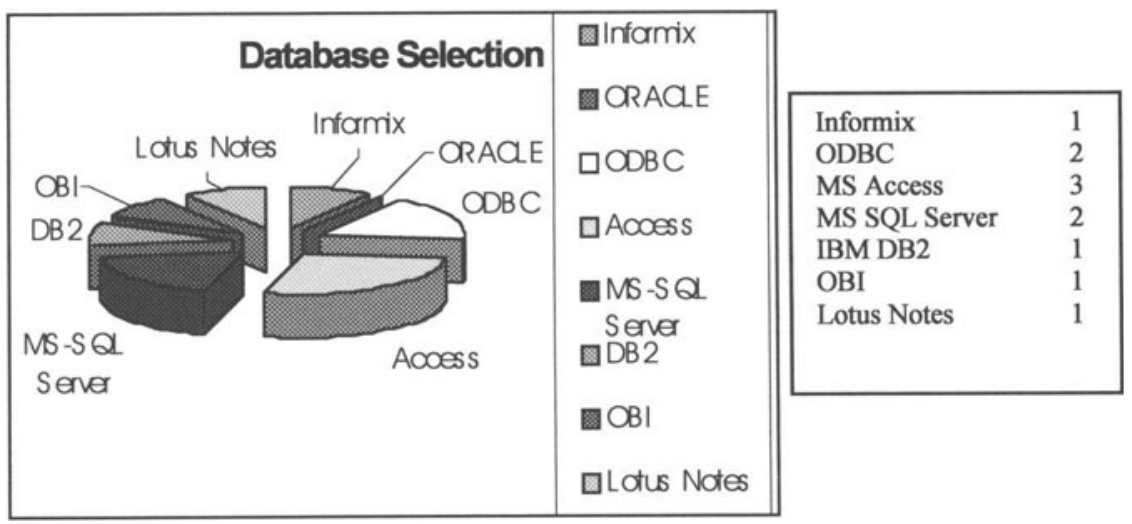

Figure 3 - Database selection

\subsection{Hosting Platform}

The answers to question 3 are shown in Figure 4

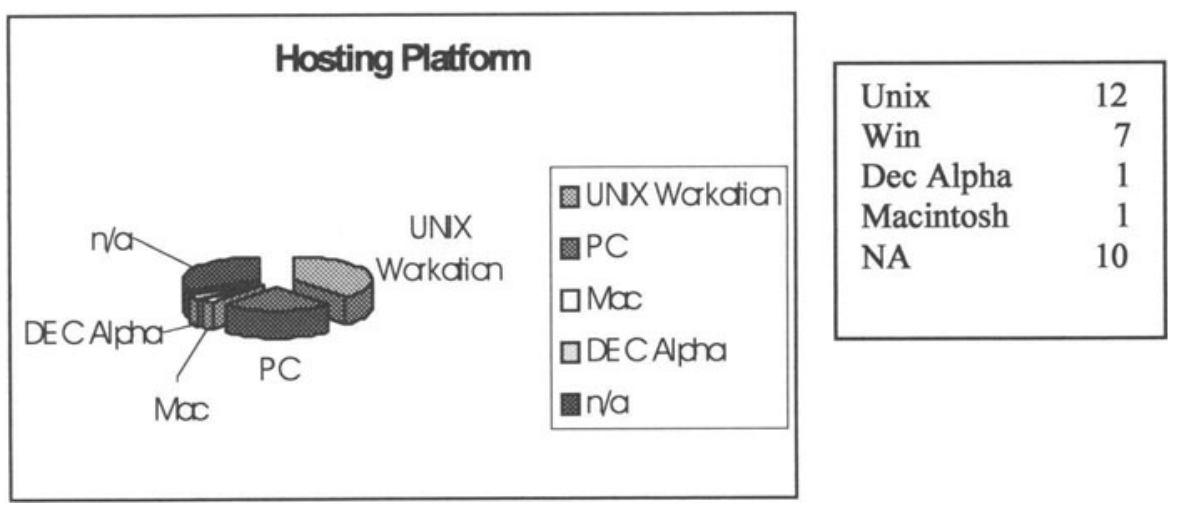

Figure 4 - Hosting Platforms 
Development Platforms Of the 12 respondents who used UNIX , 3 indicated that the system had been developed under Windows and then moved onto a UNIX host.

\subsection{Location}

The answers to question 4 are shown in Figure 5

Figure 5 - Location

\section{Conclusions}

\subsection{Response rate}

The response rate of approximately $50 \%$ is in the experience of the authors unusually high, particularly when compare to other surveys carried out at Sunderland in the field of information systems (Hardy, 94). Given the small sample size of the survey however, the results must be treated with a certain amount of caution.

\subsection{Catalogue - Bespoke vs Off-the-shelf}

Around half of the Web-based catalogue systems built use bespoke software. This suggests that Electronic Commerce is still in its infancy and that off-the-shelf software to support it has not yet reached maturity.

\subsection{Database Usage}

Only around half of the Web-based catalogue systems built use an underlying structured databases with the remainder using a flat file format for data storage. This implies that software engineering techniques have been discarded in the rush to get EC systems onto the Internet.

\subsection{Hosting Platform}

UNIX is still the most popular system for hosting websites. It would seem that website administrators prefer flexibility offered by UNIX. It is noteworthy that these are commercial systems using what was once seen as an operating systems purely for academics. This trend may also indicate the relative merits of server software supported by the various operating systems. Since the initial development of the web was UNIX based, the server software developed under UNIX has had some 3-4 years longer in which to evolve into a mature stable product. The number of respondents developing under Win95/NT and hosting on UNIX may indicate a lack of suitable UNIX based development tools. 


\subsection{Location}

Uptake of Web-based Electronic Commerce seems to be equal on both side of the Atlantic. This is surprising given the larger domestic user base in the US. This seems to indicate that European organisations are being quicker on the uptake of EC. This result is somewhat counter intuitive and needs further investigation before the position can be definitively stated.

\section{References}

Adam, N.R. \& Yesha, Y, (Eds), "Electronic Commerce: Current Research Issues and Applications", Springer-Verlag, 1996

T.J. Berners-Lee, R. Cailliau, J-F Groff, B. Pollermann, "World-Wide Web: The Information Universe", in "Electronic Networking: Research, Applications and Policy", Vol. 2 No 1, pp. 52-58 Spring 1992, Meckler Publishing, Westport, CT, USA.

Ferguson, R.I., Cranner, P., Grey, D, and Williams, A.“A Survey of Web-based

Catalogues: Original data", $\mathrm{http} / / / \mathrm{cec}$.sunderland.ac.uk/surveys/survey1/originaldata.html

Ferguson, R.I., Cranner, P., Grey, D, and Williams, A."A directory of Electronic Commerce Websites", http://cec.sunderland.ac.uk/Cec_website/links.html

Hardy C., Thompson, B. \& Edwards, H.M., "A Survey of current method usage for software development in the UK", BCS Conference on Information Systems Methodologies, Edinburgh, 1994

Kalakota, R. \& Whinston, A., "Frontiers of Electronic Commerce", AddisonWesley, 1997

Kerridge, S. "Tradepoint User Requirements Document", Unpublished Internal report of the Tradepoint Project, CEC, University of Sunderland, 1997

Net.Genesis Corporation, "Build a World Wide Web Commerce Server", Wiley, 1996

\section{Biography}

Ian Ferguson is a Senior Lecturer in Computing. With a background in Software Engineering, he has published in the fields of CASE and MetaCASE before becoming interested in the WWW in 1992. Responsible for running one of the first WWW servers in the UK, he has gone on to publish on interfacing databases to the WWW and Internet based software repositories. 